\title{
Enhanced extraction of phenolic compounds using choline chloride based deep eutectic solvents from Juglans regia L.
}

\author{
Vanessa Vieira $^{\mathrm{a}, \mathrm{b}, \mathrm{c}}$, Miguel A. Prieto ${ }^{\mathrm{b}, \mathrm{d}}$, Lillian Barros ${ }^{\mathrm{b}}$, João A.P. Coutinho ${ }^{\mathrm{a}}$, \\ Isabel C.F.R. Ferreira ${ }^{\mathrm{b}, *}$, Olga Ferreira ${ }^{\mathrm{b}, *}$ \\ ${ }^{a}$ CICECO - Aveiro Institute of Materials, Complexo de Laboratórios Tecnológicos, Aveiro University, Campus Universitário de Santiago, 3810-193 Aveiro, Aveiro, Portugal \\ ${ }^{\mathrm{b}}$ Centro de Investigação de Montanha (CIMO), Instituto Politécnico de Bragança, Campus de Santa Apolónia, 5300-253 Bragança, Portugal \\ ${ }^{\mathrm{c}}$ Laboratory of Separation and Reaction Engineering - Laboratory of Catalysis and Materials (LSRE-LCM), Polytechnic Institute of Bragança, Campus de Santa Apolónia, \\ 5300-253 Bragança, Portugal \\ ${ }^{\mathrm{d}}$ Nutrition and Bromatology Group, Faculty of Food Science and Technology, University of Vigo, Ourense Campus, E32004 Ourense, Spain
}

A R T I C L E I N F O

\section{Keywords:}

Phenolic compounds

Deep eutectic solvents

Heat-assisted extraction

Response surface methodology

Juglans regia L.

\begin{abstract}
A B S T R A C T
The extraction of phenolic compounds from walnut leaves (Juglans regia L.) was optimized using heat-assisted extraction and deep eutectic solvents based on choline chloride and carboxylic acids. A preliminary solvent screening was performed using a selected group of carboxylic acids as hydrogen bond donors, showing that the highest extraction yield of phenolic compounds was obtained using choline chloride mixtures with butyric or phenylpropionic acid at a mole ratio $1: 2$, with $20 \%$ of water $(\mathrm{w} / \mathrm{w})$. The extraction conditions (time, temperature and water proportion) were then optimized by an experimental design, assisted by response surface methodology. To evaluate the response, the three most abundant compounds identified by HPLC (neochlorogenic acid, quercetin 3-O-glucoside and quercetin $O$-pentoside) were quantified. Additionally, the solid/liquid ratio effect at the optimal conditions, in dose-response format, was studied in view of its upscale, not showing any significant decrease until $140 \mathrm{~g} / \mathrm{L}$. The results here presented provide valuable information towards the design of a process in a pre-industrial form for the extraction of phenolic compounds from $J$. regia leaves using deep eutectic solvents.
\end{abstract}

\section{Introduction}

Deep eutectic solvents (DES) were first introduced in 2003 by Abbott and co-workers (Abbott et al., 2003) reporting mixtures of urea and quaternary ammonium salts, in particular choline chloride (CC). Since then many other DES have been reported and their use proposed for a wide range of applications (Francisco et al., 2012; Smith et al., 2014). A DES is a mixture between two (or more) starting materials (hydrogen bond acceptor - HBA and hydrogen bond donor - HBD) where the eutectic temperature of the mixture is considerably lower than that of either of the constituents (Abbott et al., 2004). Some authors prefer to call them low transition temperature mixtures (Francisco et al., 2013; Jancheva et al., 2017).

The replacement of volatile and toxic organic solvents by greener and more performant solvents is one the most important challenges of our days for the chemical industry in general, and biorefineries in particular (Pena-Pereira and Namieśnik, 2014). Choi et al. (2011) introduced the DES as an alternative media to extract secondary metabolites, such as phenolic compounds, from natural matrices instead of conventional organic solvents. Nowadays, this idea is being expanded to create designer solvents, using several combinations of HBA and HBD, with tunable properties to selectively dissolve and extract natural and bioactive compounds from plants, oils or biomass, valorizing natural products or wastes as a source of valuable compounds (Dai et al., 2016; Nam et al., 2015; Paradiso et al., 2016). A very recent review on the application of deep eutectic solvents for the extraction of phenolic compounds can be found in literature, describing the possibility of using DES both as solvent and formulation media with potential cosmetics, pharmaceutical, or food applications (Ruesgas-Ramón et al., 2017).

This new generation of solvents entails several characteristics, which support their insertion in different industries. First, they are simple to prepare from cheap starting materials (Dai et al., 2016). Then, the HBA and HBD can be selected to be less toxic than organic volatile solvents and also biodegradable (Mbous et al., 2017). Moreover, in general, these solvents have low volatility and flammability (Dai et al., 2016). The addition of water to DES, for extraction purposes, is a wellestablished procedure to reduce the viscosity of the solvents and

\footnotetext{
* Corresponding authors.

E-mail addresses: iferreira@ipb.pt (I.C.F.R. Ferreira), oferreira@ipb.pt (O. Ferreira).
} 
improve the mass transfer of bioactive molecules from the natural matrices (García et al., 2016; Gu et al., 2014). Regarding temperature, its increase leads to a lower viscosity and, consequently, to higher extraction yields (Dai et al., 2016; Jancheva et al., 2017).

In the present study, the performance of choline chloride (CC) based DES combined with carboxylic acids (CA) is investigated for the extraction of phytochemical compounds from the leaves of walnut trees. Walnut leaves were chosen as a plant model as they stand out as a significant source of bioactive compounds such as phenolic acids and flavonols (Santos et al., 2013; Vieira et al., 2017). These leaves are well known in traditional medicine due to their health benefits arising from their antioxidant, antitumor (Santos et al., 2013), antiproliferative (Carvalho et al., 2010), anti-inflammatory and antinociceptive (Erdemoglu et al., 2003) activities. A DES screening of mixtures of CC and CA is carried by heat-assisted extraction (HAE). Fifteen acids were selected to assess the effect of the alkyl chain length, the number of carboxylic acid groups, and the additional presence of hydroxyl and/or phenyl groups over the extraction performance. The best two DES selected will be used to optimize the extraction conditions of time $(t)$, temperature $(T)$ and water content $(S)$ by response surface methodology (RSM). The work here presented can be better comprehended as a continuation of a previous work from other authors (Vieira et al., 2017), in which they optimized the extraction of bioactive compounds from walnut leaves using hydro-alcoholic mixtures.

\section{Material and methods}

\subsection{Standards and reagents}

HPLC-grade acetonitrile and anhydrous citric acid were from Fisher Scientific (Lisbon, Portugal). The phenolic compounds standards 5-Ocaffeoylquinc acid (Extrasynthèse, Genay, France) and quercetin 3-Oglucoside, as well as glutaric acid (99 wt\%) and glycolic acid (99 wt\%) were purchased from Sigma-Aldrich. Butyric acid ( $99 \mathrm{wt} \%)$, lactic acid (88-92 wt\%) and valeric acid (99 wt\%) were purchased from Riedel-de Haen. Acetic acid $(99.5 \mathrm{wt} \%)$ was obtained from Labsolve JMGS, propionic acid (99wt\%) from Merck, DL-malic acid (99.5 wt\%) from Panreac, malonic acid (98 wt\%) from Fluka, phenyl-acetic acid (99 wt $\%)$ from Alfa Aesar. Choline chloride (98 wt\%), 3-phenylpropionic acid (99 wt\%), 4-phenylbutyric acid (99 wt\%) and 5-phenylvaleric acid ( $99 \mathrm{wt} \%$ ) from ACROS Organics. All the other chemicals were of analytical grade and purchased from common sources.

\subsection{Plant material}

Juglans regia L. (walnut) dried leaves were purchased from Soria Natural, S.A., Spain. According to the distributor, the leaves were collected in Soria (Spain) in June 2014 and naturally dried in a room with controlled humidity. The samples were reduced to a fine dried powder (60-20 mesh) and stored in a desiccator protected from light for subsequent assays.

\subsection{Screening analysis of DES}

\subsubsection{Preparation of DES}

DES were prepared using the heating-stirring method proposed by Abbot and co-workers (Abbott et al., 2004) with slight modifications. Firstly, the water amount present in the starting materials was measured using a Metrohm 831 Karl Fisher coulometer (data not shown). Then, each component was accurately weighed $\left( \pm 10^{-4} \mathrm{~g}\right.$ ) to a roundbottom flask. The mixtures were stirred in a water bath (from 50 to $80^{\circ} \mathrm{C}$ ) at $600 \mathrm{rpm}$ until a homogenous solvent was obtained. The resulting DES are listed in Table 1.

\subsubsection{Conditions for the screening extraction by heat-assisted extraction} For the screening extractions, DES were prepared with $20 \%(w / w)$ of water except for phenylbutyric and phenylvaleric acids that were prepared with $5 \%(\mathrm{w} / \mathrm{w})$ of water due to their low solubility in water. For comparison purposes, the DES CC:phenylpropionic acid was also prepared with $5 \%$ of water.

The solid-liquid heat assisted extractions (HAE) were performed using a Carousel 12 Plus Reaction Station ${ }^{\mathrm{TM}}$ (Radleys Tech). This equipment allows stirring and temperature control within $\pm 0.5^{\circ} \mathrm{C}$, with protection from light. It is also coupled to a condensation system, avoiding the loss of solvent. The powdered samples $(0.15 \mathrm{~g})$ were extracted with $5 \mathrm{~mL}$ of each solvent, during $60 \mathrm{~min}$ at $50{ }^{\circ} \mathrm{C}$ and $600 \mathrm{rpm}$. A control extraction using the conventional solvent ethanol:water (1:1, $v / v$ ) was also performed. After extraction, the mixtures were centrifuged at $6000 \mathrm{rpm}$ during $10 \mathrm{~min}$ at room temperature and the supernatant was filtered through a Whatman $\mathrm{n}^{\circ} 4$ for further analysis. For the extracts obtained with choline chloride:aromatic acids, a previous dilution was made with methanol due to thermal and physical stability.

\subsection{Chromatographic analysis of the main phenolic compounds}

Extract solutions were two-fold diluted with water and filtered through $0.2 \mu \mathrm{m}$ disposable LC filter disks $(30 \mathrm{~mm}$, regenerated cellulose). The DES composed by CC and aromatic acids were diluted with methanol to avoid precipitation at room temperature. The samples were analysed as previously applied (Vieira et al., 2017) using a Shimadzu 20A series UFLC (Shimadzu Corporation, Kyoto, Japan) with a quaternary pump and a photodiode array detector (PDA) coupled to an LC solution software data-processing station using a Waters Spherisorb S3 ODS-2 $\mathrm{C}_{18},(3 \mu \mathrm{m}, 4.6 \mathrm{~mm} \times 150 \mathrm{~mm})$ column operating at $35^{\circ} \mathrm{C}$ for separation. Double online detection was carried with a diode array detector (DAD) operating at 280 and $370 \mathrm{~nm}$ as preferred wavelengths and the target phenolic compounds were identified according to their UV spectra and retention time (Barros et al., 2013). The results were expressed in mg per $\mathrm{g}$ of dry weight $(\mathrm{mg} / \mathrm{g} \mathrm{dw})$.

\subsection{HAE optimization by RSM of the selected DES, experimental design, model analysis and statistical evaluation}

An illustrative diagram of the different steps carried out to obtain an optimal phenolic extract from $J$. regia L. is presented in Figure A1 . The solid-liquid extractions were performed with the HAE using the same equipment above described for the DES screening.

\subsubsection{Experimental design}

The study of the impact of all independent variables was carried using one-factor-at-a-time, to identify the most influent, and to determine the initial range of the processing variables. Through the analysis of this experimental results (data not shown), $X_{1}(t, \mathrm{~min}), X_{2}(T$, in $\left.{ }^{\circ} \mathrm{C}\right)$ and $X_{3}(S$, in\%) were chosen as variables for the RSM design. Therefore, the combined effect of these variables on the extraction of the three main phenolic compounds present in $J$. regia (maximizing responses individually or globally) was studied using circumscribed central composite design (CCCD) with 5 levels of each factor. The experimental design is based on 20 independent combinations, 6 of which are replicas at the central point of the experiment Box and Hunter (1957). The mathematical expressions used to calculate the design distribution, code and decode the tested variables can be found all detailed in the supplemental section (supplementary material). Once the optimal conditions $\left(X_{1}, X_{2}\right.$ and $\left.X_{3}\right)$ were optimized, the study was advanced furthermore with the study of the $S / L$ condition $\left(X_{4}\right.$, in $\left.\mathrm{g} / \mathrm{L}\right)$.

\subsubsection{Mathematical model}

The response surface models were fitted by means of least-squares calculations using the following second-order polynomial equation: 
Table 1

Composition and responses of the set of DES used in the initial screening for the selection of the HBD.

\begin{tabular}{|c|c|c|c|c|}
\hline SOLVENT & \multicolumn{4}{|c|}{ HPLC-DAD RESPONSES $(m g / g d w)$} \\
\hline REFERENCE SOLVENTS & $\mathrm{P} 1$ & $\mathrm{P} 2$ & P3 & TOTAL \\
\hline Water & 5.4 & 1.3 & 2.1 & 8.8 \\
\hline Ethanol & 0.4 & 4.8 & 5.0 & 10.3 \\
\hline $\begin{array}{l}\text { Ethanol + water }(50: 50, \% v / \\
\quad v)\end{array}$ & 4.9 & 11.3 & 8.6 & 24.9 \\
\hline
\end{tabular}

\begin{tabular}{|c|c|c|c|c|c|c|c|c|}
\hline \multirow{2}{*}{\multicolumn{3}{|c|}{$\begin{array}{l}\text { DEEP EUTECTIC SOLVENTS (DES) } \\
\text { COMPOSITION }\end{array}$}} & & & \multicolumn{4}{|c|}{ HPLC-DAD RESPONSES $(m g / g d w)$} \\
\hline & & & \multicolumn{2}{|l|}{ PROPORTIONS } & \multirow[t]{2}{*}{$\mathrm{P} 1$} & \multirow[t]{2}{*}{$\mathrm{P} 2$} & \multirow[t]{2}{*}{ P3 } & \multirow[t]{2}{*}{ TOTAL } \\
\hline $\mathrm{C} 1$ & $\mathrm{C} 2$ & $\mathrm{C} 3$ & $\mathrm{C} 1: \mathrm{C} 2(\mathrm{~mol} / \mathrm{mol})$ & $\mathrm{C} 3(\%, w / w)$ & & & & \\
\hline CC & Acetic acid & $\mathrm{H}_{2} \mathrm{O}$ & $(1: 2)$ & 20 & 4.9 & 13.1 & 10.3 & 28.2 \\
\hline $\mathrm{CC}$ & Propionic acid & $\mathrm{H}_{2} \mathrm{O}$ & $(1: 2)$ & 20 & 7.8 & 13.8 & 11.7 & 33.3 \\
\hline CC & Butyric acid & $\mathrm{H}_{2} \mathrm{O}$ & $(1: 2)$ & 20 & 7.3 & 14.4 & 12.0 & 33.7 \\
\hline CC & Valeric acid & $\mathrm{H}_{2} \mathrm{O}$ & $(1: 2)$ & 20 & 5.4 & 11.0 & 9.5 & 25.9 \\
\hline CC & Glycolic acid & $\mathrm{H}_{2} \mathrm{O}$ & $(1: 2)$ & 20 & 6.2 & 10.1 & 6.3 & 22.6 \\
\hline CC & Lactic acid & $\mathrm{H}_{2} \mathrm{O}$ & $(1: 2)$ & 20 & 5.7 & 9.9 & 6.8 & 22.3 \\
\hline $\mathrm{CC}$ & Phenylacetic acid & $\mathrm{H}_{2} \mathrm{O}$ & $(1: 2)$ & 20 & 4.9 & 14.7 & 11.6 & 31.1 \\
\hline CC & 3-Phenylpropionic acid & $\mathrm{H}_{2} \mathrm{O}$ & $(1: 2)$ & 20 & 5.4 & 15.4 & 13.4 & 34.3 \\
\hline CC & Malic acid & $\mathrm{H}_{2} \mathrm{O}$ & $(1: 1)$ & 20 & 5.0 & 8.6 & 5.6 & 19.2 \\
\hline CC & Malonic acid & $\mathrm{H}_{2} \mathrm{O}$ & $(1: 1)$ & 20 & 5.6 & 10.5 & 5.3 & 21.2 \\
\hline CC & Glutaric acid & $\mathrm{H}_{2} \mathrm{O}$ & $(1: 1)$ & 20 & 4.4 & 9.7 & 7.0 & 21.2 \\
\hline CC & Citric acid & $\mathrm{H}_{2} \mathrm{O}$ & $(2: 1)$ & 20 & 4.4 & 6.5 & 4.1 & 14.9 \\
\hline $\mathrm{CC}$ & 3-Phenylpropionic acid & $\mathrm{H}_{2} \mathrm{O}$ & $(1: 2)$ & 5 & 2.5 & 6.3 & 5.5 & 14.3 \\
\hline CC & 4-Phenylbutyric acid & $\mathrm{H}_{2} \mathrm{O}$ & $(1: 2)$ & 5 & 3.8 & 8.3 & 6.7 & 18.8 \\
\hline $\mathrm{CC}$ & 5-Phenylvaleric acid & $\mathrm{H}_{2} \mathrm{O}$ & $(1: 2)$ & 5 & 2.1 & 6.5 & 5.2 & 13.8 \\
\hline
\end{tabular}

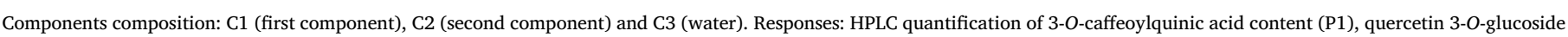
content (P2), quercetin O-pentoside content (P3) and total HPLC content (TOTAL, P1 + P2 + P3).

$Y=b_{0}+\sum_{i=1}^{n} b_{i} X_{i}+\sum_{\substack{i=1 \\ j>i}}^{n-1} \sum_{j=2}^{n} b_{i j} X_{i} X_{j}+\sum_{i=1}^{n} b_{i i} X_{i}^{2}$

In this equation, $Y$ represents the dependent variable (response variable) to be modelled, the independent variables are $X_{i}$ and $X_{j}, b_{o}$ is the constant coefficient, $b_{i}$ the coefficient of linear effect, $b_{i j}$ the coefficient of interaction effect, $b_{i i}$ the coefficients of quadratic effect and $n$ is the number of variables. The responses used for evaluating the extraction process were: 1 ) the main HPLC compounds identified of as the phenolic acid 3-O-caffeoylquinic acid (P1) and two flavonols, quercetin 3$O$-glucoside (P2), and quercetin $O$-pentoside (P3); and 2) the total HPLC compounds determined (P1 + P2 + P3).

\subsubsection{Procedure to optimize the variables to a maximum response}

A simplex method was used to maximize the model process by solving non-linear problems to optimize the response criteria selected (P1, P2, P3 and total HPLC) (Heleno et al., 2016; Pinela et al., 2016). To avoid unnatural conditions of the variables, certain limitations were imposed (i.e., times lower than 0).

\subsubsection{Fitting procedures and statistical analysis}

The statistical analysis and fitting was obtained using a Microsoft Excel spreadsheet in three phases as explained in detail previously (Vieira et al., 2017). Briefly: 1) Coefficients measurement was achieved using the nonlinear least-square (quasi-Newton) in Microsoft Excel (Kemmer and Keller, 2010); 2) Coefficients significance was obtained via 'SolverAid' (Prieto et al., 2014); and 3) Model reliability was confirmed by applying Fisher $F$-test $(\alpha=0.05)$ (Pinela et al., 2017) and the 'SolverStat' macro was used to make assessment of parameter and model prediction uncertainties (Prieto et al., 2015).

\section{Results and discussion}

\subsection{DES screening to investigate the effect of CA molecular structure on the extraction of phytochemical compounds}

Phenolic compounds are complex molecules, and their extraction from a solid matrix requires compatible solvents. The responses used to evaluate the efficiency of the extraction were the specific quantification of the phenolic compounds performed by HPLC-DAD (P1, P2 and P3) as described before (Vieira et al., 2017). The phenolic profile of $J$. regia leaves extracts is in good agreement with the previously reported by Santos et al. (2013) (supplementary material). These compounds were identified by comparison of their UV spectra and retention times with those obtained in previous findings, as well as with the commercial standards.

In this work, DES formed by CC and CA were evaluated to investigate the effect of the acid's molecular structure on the extraction of compounds from J. regia L. To study the effect of the chemical structure of the hydrogen bond donor upon the extraction efficiency of the DES, different acid groups were chosen: linear monocarboxylic acids (acetic acid, propionic acid, butyric acid and valeric acid), aromatic acids (phenylacetic, 3-phenylpropionic, 4-phenylbutyric acid and 5-phenylvaleric acids), dicarboxylic acids (malonic and glutaric acids), hydroxy monocarboxylic acids (glycolic acid and lactic acid), one hydroxy dicarboxylic acid (malic acid) and one hydroxy tricarboxylic acid (citric acid). The CA:CC mole ratio was chosen according to the eutectic composition found by Abbott et al. (2004): 2:1 for monocarboxylic acids (phenylacetic and 3-phenylpropionic acids); 1:1 for dicarboxylic acids (malonic acid), and 1:2 for tricarboxylic acids (citric acid). To decrease the systems viscosity, a given amount of water $(20 \%, w / w)$ was added to the DES. For the systems CC:phenylbutyric acid and CC:phenylvaleric acid, only $5 \% w / w$ water was added because of miscibility issues. For comparison purposes, CC:phenylpropionic acid was studied at $5 \%$ and $20 \%$ water content. In this screening, the following extraction conditions were adopted: $1 \mathrm{~h}$ extraction time, $50{ }^{\circ} \mathrm{C}$ and $600 \mathrm{rpm}$ stirring speed. In addition, water, pure ethanol and 


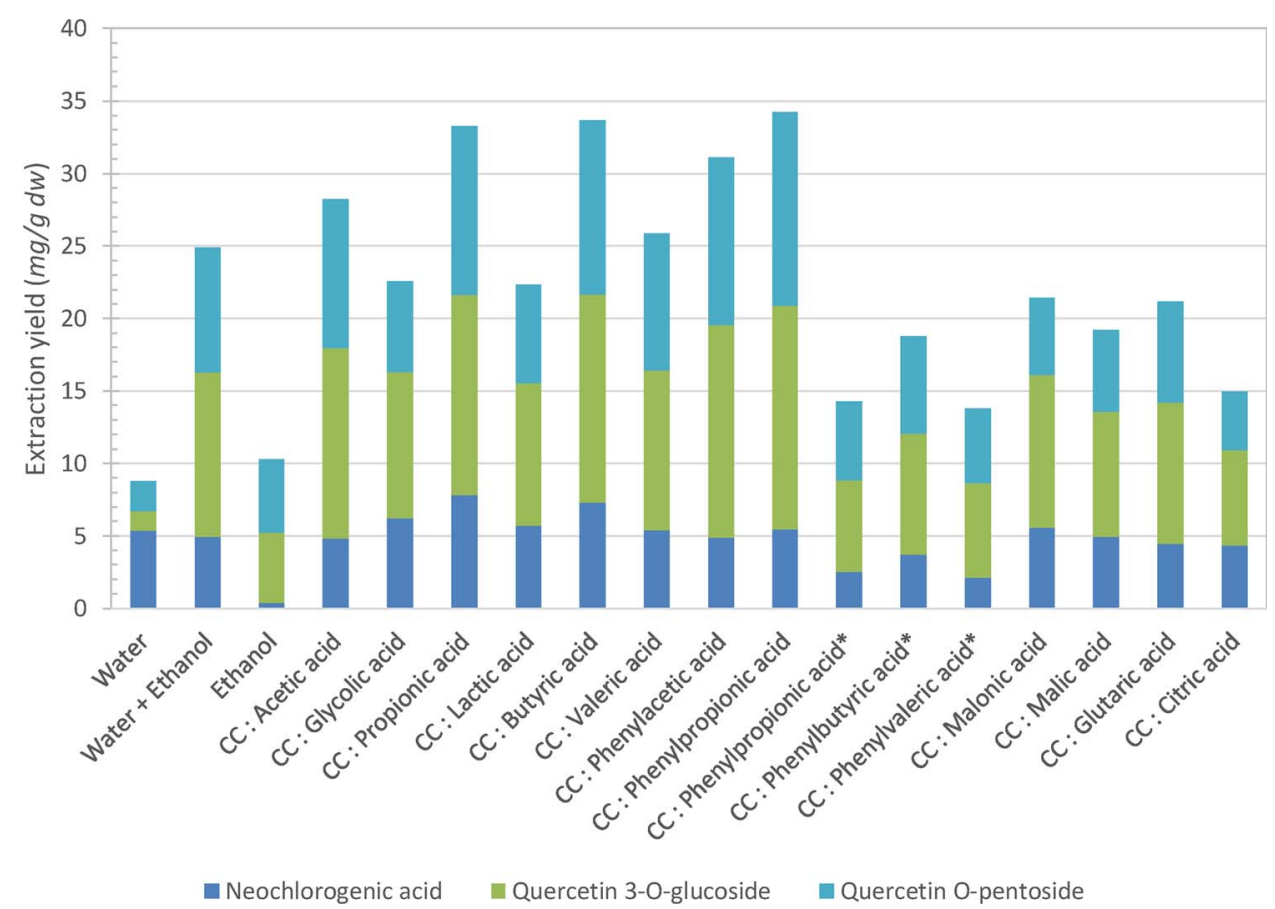

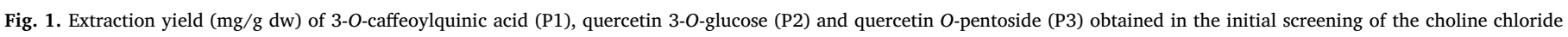
based DES described in Table 1, with the extraction conditions: $1 \mathrm{~h}$ extraction time, $50{ }^{\circ} \mathrm{C}, 600 \mathrm{rpm}$ and $20 \%$ (w/w) of water (solvents with * only contain $5 \%$ (w/w) of water).

ethanol:water $(1: 1, v / v)$ were also used as extraction solvents at the same conditions, for comparison purposes.

Fig. 1 shows the results obtained for the extraction yield using the selected set of DES and reference solvents. Detailed data are reported in Table 1. The following conclusions were derived:

1) The total amount of phenolic compounds detected $(\mathrm{P} 1+\mathrm{P} 2+\mathrm{P} 3)$ for the reference solvents, at the screening extraction conditions, were $8.8 \pm 0.1 \mathrm{mg} / \mathrm{g} \mathrm{dw}$ for water, $10.3 \pm 0.01 \mathrm{mg} / \mathrm{g} \mathrm{dw}$ for ethanol and $24.9 \pm 0.1 \mathrm{mg} / \mathrm{g} \mathrm{dw}$ for ethanol:water $(1: 1, v / v)$. The phenolic profile showed significant differences depending on the solvent applied. Water extracted mainly the polar compound P1 (3$O$-caffeoylquinic acid) and only traces of the quercetin derivatives (P2 and P3). Meanwhile, when pure ethanol was used, only a small fraction of $\mathrm{P} 1$ is detected $(\sim 0.4 \mathrm{mg} / \mathrm{g})$ favoring the extraction of less polar compounds (P2 and $\mathrm{P} 3$ ). These results were in accordance to the results previously reported by Vieira et al. (2017), in which the mixture ethanol/water was the most adequate combination.

2) For DES with $20 \%$ water content, monocarboxylic acids (aliphatic or aromatic) led to higher extraction yields (phenylpropionic > butyric $>$ propionic $>$ phenylacetic $>$ acetic $>$ valeric $>$ glycolic $>$ lactic acid), followed by dicarboxylic acids (malonic, glutaric and malic acid) and the tricarboxylic acid (citric acid). For the solvents prepared with only $5 \%$ of water, in general, lower extraction yields are obtained. However, an increase is observed going from phenylpropionic acid to phenylbutyric acid, followed by a decrease when using phenylvaleric acid.

3) Regarding the structural differences, some tendencies can be observed by looking at the solvents containing $20 \%$ of water. The addition of a hydroxyl group $(-\mathrm{OH})$ to the acid structure, leads to lower extraction yields (e.g. pairs glycolic/acetic acids or lactic/ propionic acids). Regarding the alkyl chain length of the linear monocarboxylic acids, the increase until four carbon atoms seems to be favorable. The presence of a phenyl group also seems to promote a slight increase of the extraction yield (see phenylacetic/acetic acids or phenylpropanoic/propanoic acids). Overall, for the acids based DES, the higher the number of $-\mathrm{OH}$ and $-\mathrm{COOH}$ groups present in the solvent, the lower the extraction yield, being the target molecules preferentially extracted by acids with three/four carbons in its linear alkyl chain.

4) Analyzing the individual extraction response of the main phenolic components determined by HPLC (P1, P2 and P3), additional conclusions can be drawn. The component P1 was preferentially extracted by CC:propionic acid $(7.84 \pm 0.04 \mathrm{mg} / \mathrm{g} \mathrm{dw})$ and CC:butyric acid $(7.30 \pm 0.03 \mathrm{mg} / \mathrm{g} \mathrm{dw})$. Nevertheless, P2 and P3 are preferentially extracted by DES based on CC and aromatic acids reaching $15.44 \pm 0.01 \mathrm{mg} / \mathrm{g} \mathrm{dw}$, and $13.37 \pm 0.13 \mathrm{mg} / \mathrm{g} \mathrm{dw}$, respectively, using CC:phenylpropionic acid. Good results are also obtained for CC:butyric acid and CC:phenylacetic acid.

5) All effects combined, the solvents that presented the higher extraction yields were the mixtures of CC combined with phenylpropionic (with $20 \%$ water) $(34.3 \pm 0.2 \mathrm{mg} / \mathrm{g} \mathrm{dw})$ or butyric acid $(33.7 \pm 0.4 \mathrm{mg} / \mathrm{g} \mathrm{dw})$, closely followed by CC and propionic acid $(33.3 \pm 0.12 \mathrm{mg} / \mathrm{g} \mathrm{dw})$.

The mixtures of CC with phenylpropionic acid (PPA) or butyric acid (BA) were then selected for further optimization.

\subsection{Response criteria for the RSM analysis and statistical verification}

The extraction of target compounds from matrices requires a specific consideration due to the intrinsic nature and stability of these target compounds. Therefore, to maximize the response extraction of these compounds, it is essential to identify the response effects caused by the main variables involved using the minimum time, energy and solvent consumption and designing the most cost-effective and profitable extraction system (Dai and Mumper, 2010). The RSM design allows optimizing all the variables simultaneously considering interactive reactions and to predict the most efficient conditions. This is achieved by using second order polynomial models with interactions, that are able to describe and maximize the response criteria selected, based on the experimental range tested (Bezerra et al., 2008; Ferreira et al., 2007; Kalil and Maugeri, 2000).

The RSM experiment was designed based on the preliminary tests described above, using five levels of extraction $t, T$ and $S$ as independent variables to efficiently optimize the HAE process. The coded 
Table 2

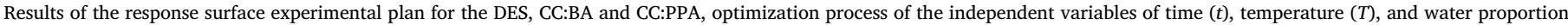

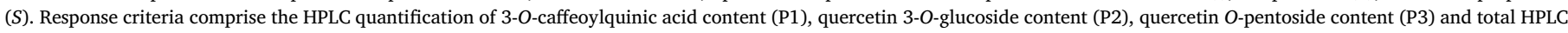
content (TOTAL, P1 + P2 + P3).

\begin{tabular}{|c|c|c|c|c|c|c|c|c|c|c|c|c|c|c|c|c|c|}
\hline & \multicolumn{9}{|c|}{ EXPERIMENTAL DESIGN } & \multirow{2}{*}{\multicolumn{4}{|c|}{$\begin{array}{l}\text { CC:BA } \\
\text { HPLC CONTENT }\end{array}$}} & \multirow{2}{*}{\multicolumn{4}{|c|}{$\begin{array}{l}\text { CC:PPA } \\
\text { HPLC CONTENT }\end{array}$}} \\
\hline & \multicolumn{3}{|c|}{ CODED VALUES } & \multicolumn{3}{|l|}{$C C: B A$} & \multicolumn{3}{|c|}{$C C: P P A$} & & & & & & & & \\
\hline & $X_{1}$ & $X_{2}$ & $X_{3}$ & $\begin{array}{l}X_{1}: t \\
\min \end{array}$ & $\begin{array}{l}X_{2}: T \\
{ }^{\circ} \mathrm{C}\end{array}$ & $\begin{array}{l}X_{3}: S \\
\%\end{array}$ & $\begin{array}{l}X_{1}: t \\
{ }^{\circ} \mathrm{C}\end{array}$ & $\begin{array}{l}X_{2}: T \\
w\end{array}$ & $\begin{array}{l}X_{3}: S \\
\%\end{array}$ & $\begin{array}{l}P 1 \\
\mathrm{mg} / \mathrm{g} \mathrm{dw}\end{array}$ & $\begin{array}{l}P 2 \\
\mathrm{mg} / \mathrm{g} \mathrm{dw}\end{array}$ & $\begin{array}{l}P 3 \\
\mathrm{mg} / \mathrm{g} \mathrm{dw}\end{array}$ & $\begin{array}{l}\text { TOTAL } \\
\mathrm{mg} / \mathrm{g} \mathrm{dw}\end{array}$ & $\begin{array}{l}P 1 \\
\mathrm{mg} / \mathrm{g} \mathrm{dw}\end{array}$ & $\begin{array}{l}P 2 \\
\mathrm{mg} / \mathrm{g} \mathrm{dw}\end{array}$ & $\begin{array}{l}P 3 \\
\mathrm{mg} / \mathrm{g} \mathrm{dw}\end{array}$ & $\begin{array}{l}\text { TOTAL } \\
\mathrm{mg} / \mathrm{g} \mathrm{dw}\end{array}$ \\
\hline 1 & -1 & -1 & -1 & 60.4 & 42.2 & 20.3 & 60.4 & 42.2 & 4.1 & 5.0 & 12.1 & 10.5 & 27.6 & 1.2 & 3.6 & 3.1 & 7.9 \\
\hline 2 & 1 & -1 & -1 & 149.6 & 42.2 & 20.3 & 149.6 & 42.2 & 4.1 & 6.0 & 14.0 & 12.0 & 32.0 & 2.3 & 7.2 & 6.2 & 15.7 \\
\hline 3 & -1 & 1 & -1 & 60.4 & 77.9 & 20.3 & 60.4 & 77.9 & 4.1 & 6.3 & 14.4 & 12.5 & 33.2 & 2.3 & 7.1 & 5.8 & 15.3 \\
\hline 4 & 1 & 1 & -1 & 149.6 & 77.9 & 20.3 & 149.6 & 77.9 & 4.1 & 5.9 & 13.5 & 11.2 & 30.6 & 3.2 & 10.2 & 7.1 & 20.4 \\
\hline 5 & -1 & -1 & 1 & 60.4 & 42.2 & 79.7 & 60.4 & 42.2 & 16 & 6.5 & 11.3 & 9.0 & 26.8 & 4.7 & 14.2 & 12.1 & 31.0 \\
\hline 6 & 1 & -1 & 1 & 149.6 & 42.2 & 79.7 & 149.6 & 42.2 & 16 & 6.6 & 11.3 & 9.0 & 26.9 & 4.8 & 14.8 & 12.9 & 32.5 \\
\hline 7 & -1 & 1 & 1 & 60.4 & 77.9 & 79.7 & 60.4 & 77.9 & 16 & 7.2 & 12.1 & 9.6 & 28.9 & 4.5 & 14.2 & 11.1 & 29.8 \\
\hline 8 & 1 & 1 & 1 & 149.6 & 77.9 & 79.7 & 149.6 & 77.9 & 16 & 6.5 & 11.0 & 8.4 & 25.9 & 4.6 & 13.8 & 9.3 & 27.6 \\
\hline 9 & -1.68 & 0 & 0 & 30 & 60 & 50 & 30 & 60 & 10 & 6.4 & 14.1 & 12.2 & 32.8 & 3.0 & 9.5 & 8.2 & 20.8 \\
\hline 10 & 1.68 & 0 & 0 & 180 & 60 & 50 & 180 & 60 & 10 & 6.8 & 15.0 & 12.6 & 34.4 & 4.7 & 14.9 & 12.3 & 31.9 \\
\hline 11 & 0 & -1.68 & 0 & 105 & 30 & 50 & 105 & 30 & 10 & 6.6 & 15.2 & 13.1 & 35.0 & 2.7 & 8.4 & 7.4 & 18.5 \\
\hline 12 & 0 & 1.68 & 0 & 105 & 90 & 50 & 105 & 90 & 10 & 6.6 & 14.2 & 10.3 & 31.1 & 3.9 & 12.4 & 7.8 & 24.0 \\
\hline 13 & 0 & 0 & -1.68 & 105 & 60 & 0 & 105 & 60 & 0 & 2.6 & 2.6 & 6.7 & 2.6 & 1.1 & 4.0 & 3.5 & 8.6 \\
\hline 14 & 0 & 0 & 1.68 & 105 & 60 & 100 & 105 & 60 & 20 & 7.2 & 5.6 & 5.5 & 18.2 & 5.0 & 15.8 & 13.1 & 34.0 \\
\hline 15 & 0 & 0 & 0 & 105 & 60 & 50 & 105 & 60 & 10 & 6.6 & 14.6 & 12.5 & 33.6 & 3.8 & 12.2 & 10.3 & 26.3 \\
\hline 16 & 0 & 0 & 0 & 105 & 60 & 50 & 105 & 60 & 10 & 6.4 & 14.3 & 12.3 & 32.9 & 4.0 & 13.1 & 11.1 & 28.3 \\
\hline 17 & 0 & 0 & 0 & 105 & 60 & 50 & 105 & 60 & 10 & 7.3 & 16.0 & 13.6 & 36.9 & 4.0 & 12.7 & 10.8 & 27.5 \\
\hline 18 & 0 & 0 & 0 & 105 & 60 & 50 & 105 & 60 & 10 & 6.4 & 14.1 & 12.3 & 32.8 & 3.5 & 11.6 & 9.8 & 25.0 \\
\hline 19 & 0 & 0 & 0 & 105 & 60 & 50 & 105 & 60 & 10 & 6.8 & 15.3 & 13.0 & 35.1 & 3.6 & 11.7 & 9.7 & 25.0 \\
\hline 20 & 0 & 0 & 0 & 105 & 60 & 50 & 105 & 60 & 10 & 6.5 & 14.8 & 12.5 & 33.8 & 3.7 & 11.8 & 9.9 & 25.4 \\
\hline
\end{tabular}

values and their natural values are presented in Table A1. Once the optimal conditions ( $t, T$ and $S$ ) were optimized, the study was further advanced towards the study of the effects of the $S / L$.

Experimental conditions of BA and PPA, and chromatographic response results (HPLC-PDA) are presented in Table 2 for the CCCD RSM design. The quantification results obtained from the chromatographic methodology were used as response criteria to optimize the solvents conditions by RSM. The obtained parametric fitting values, confidence intervals and statistical information are presented in Table 3.

\subsubsection{Theoretical response surface models predicted}

The RSM mathematical models were obtained by fitting each individual response (experimental values in Table 2) to the second-order polynomial model of Eq. (1) using nonlinear least-squares estimations. The resulting models for each assessed extraction technique are the following, for the CC:BA system:

Table 3

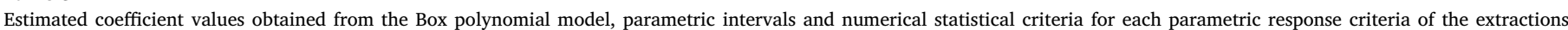

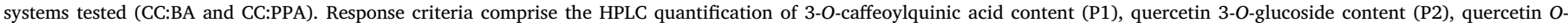
pentoside content (P3) and total HPLC content (P1 + P2 + P3).

\begin{tabular}{|c|c|c|c|c|c|}
\hline \multirow[t]{2}{*}{ PARAMETERS } & & \multicolumn{4}{|l|}{ HPLC CONTENT } \\
\hline & & $P 1$ & $P 2$ & P3 & TOTAL \\
\hline \multicolumn{6}{|l|}{$C C: B A$} \\
\hline Intercept & $\mathrm{b}_{0}$ & $6.71 \pm 0.18$ & $15.17 \pm 0.18$ & $12.69 \pm 0.44$ & $34.52 \pm 0.63$ \\
\hline \multirow{3}{*}{ Linear effect } & $\mathrm{b}_{1}$ & $\mathrm{~ns}$ & $\mathrm{~ns}$ & ns & ns \\
\hline & $\mathrm{b}_{2}$ & $0.16 \pm 0.03$ & ns & $-0.32 \pm 0.09$ & ns \\
\hline & $\mathrm{b}_{3}$ & $0.77 \pm 0.17$ & ns & $-0.75 \pm 0.09$ & $1.47 \pm 0.20$ \\
\hline \multirow[t]{3}{*}{ Quadratic effect } & $\mathrm{b}_{11}$ & ns & ns & $0.09 \pm 0.07$ & $0.26 \pm 0.20$ \\
\hline & $b_{22}$ & ns & ns & $-0.40 \pm 0.09$ & ns \\
\hline & $\mathrm{b}_{33}$ & $-0.62 \pm 0.16$ & $-3.32 \pm 0.18$ & $-2.17 \pm 0.09$ & $-7.23 \pm 0.20$ \\
\hline \multirow[t]{3}{*}{ Interactive effect } & $b_{12}$ & $-0.13 \pm 0.02$ & $-0.30 \pm 0.18$ & ns & $-0.91 \pm 0.20$ \\
\hline & $\mathrm{b}_{13}$ & ns & $-0.24 \pm 0.18$ & ns & ns \\
\hline & $\mathrm{b}_{23}$ & ns & ns & $\mathrm{ns}$ & ns \\
\hline Statistics $\left(\mathrm{R}^{2}\right)$ & & 0.8340 & 0.8445 & 0.8576 & 0.9229 \\
\hline \multicolumn{6}{|l|}{$C C: P P A$} \\
\hline Intercept & $\mathrm{b}_{0}$ & 3.80 & 12.03 & 10.22 & 26.18 \\
\hline \multirow[t]{3}{*}{ Linear effect } & $\mathrm{b}_{1}$ & 0.37 & 1.23 & ns & 2.34 \\
\hline & $b_{2}$ & 0.30 & 1.00 & -0.32 & 1.46 \\
\hline & $\mathrm{b}_{3}$ & 1.27 & 3.42 & -0.75 & 7.07 \\
\hline \multirow[t]{3}{*}{ Quadratic effect } & $\mathrm{b}_{11}$ & ns & ns & 0.09 & ns \\
\hline & $b_{22}$ & -0.36 & -0.39 & -0.40 & -1.43 \\
\hline & $b_{33}$ & $\mathrm{~ns}$ & -0.95 & -2.17 & -2.43 \\
\hline \multirow[t]{3}{*}{ Interactive effect } & $\mathrm{b}_{12}$ & $\mathrm{~ns}$ & ns & $\mathrm{ns}$ & -0.97 \\
\hline & $\mathrm{b}_{13}$ & -0.19 & -0.62 & ns & -1.50 \\
\hline & $\mathrm{b}_{23}$ & -0.19 & -0.61 & $\mathrm{~ns}$ & -1.29 \\
\hline Statistics $\left(\mathrm{R}^{2}\right)$ & & 0.9407 & 0.9609 & 0.9671 & 0.9491 \\
\hline
\end{tabular}


$Y_{P 1}^{B A}=6.71+0.16 T+0.77 S-0.62 S^{2}-0.13 t T$

$Y_{P 2}^{B A}=15.17-3.32 S^{2}-0.20 t T-0.30 t S$

$Y_{P 3}^{B A}=12.69-0.32 T-0.75 S+0.09 t^{2}-0.40 T^{2}-2.17 S^{2}$

$Y_{P 1+P 2+P 3}^{B A}=34.52+1.47 S+0.26 t^{2}-7.23 S^{2}-0.91 t T$

And for the CC:PPA system:

$$
\begin{array}{rl}
Y_{P 1}^{P P A}= & 3.80+0.37 t+0.30 T+1.27 S-0.36 T^{2}-0.19 t S-0.19 T S \\
Y_{P 2}^{P P A}= & 12.03+1.23 t+1.00 T+3.42 S-0.39 T^{2}-0.95 S^{2}-0.62 t T \\
& -0.61 T S \\
Y_{P 3}^{P P A}= & 10.22-0.32 t-0.75 T+0.09 S-0.40 t^{2}-2.17 T^{2} \\
Y_{P 1+P 2+P 3}^{P P A} & 26.18+2.34 t+1.46 T+7.07 S-1.43 T^{2}-2.43 S^{2}-0.97 t T \\
& \quad-1.50 t S-1.29 T S
\end{array}
$$

These equations translate the response patterns for individual measurement of phenolic compounds and Table 3 shows the complexity of possible sceneries. Not all the parameters of Eq. (1) were used for building the model since some coefficients were non-significant ( $n s)$. The significant parametric coefficients were tested with intervals of confidence at the $95 \%$ level $(\alpha=0.05)$ and the correlation coefficients were always higher than 0.87 .

The models presented in Eqs. (2)-(0) are workable showing a good agreement between the experimental and predicted values, which proves that they can be used for the prediction and optimization stages. Additionally, all independent variables used show significant variations, which means that they are needed for complete understanding of the behavior of responses. The significant parametric values found in those models cannot be linked with physical or chemical significance, but they are valuable to predict the results of untested operation conditions (Ranic et al., 2014). The sign of the parametric value determines part of the response; for positive effects, the response is higher at the high level and when a factor has a negative effect, the response is lower at high level. Additionally, the higher of the parametric value, the more significant the weight of the governing variable is.

Certain features of the parametric values of the variables display similar effects in both DES tested: 1) the relevance of the significant parametric values can be ranked as a function of the variables involved in the following decreasing form as $S>>T>t$; 2) Linear, quadratic and interactive parametric effects of the equations developed play a relevant role on the responses achieved; and 3) All the interactive parametric values show a negative effect, which reveals that in all of them the increase of the interacting variables reduces the expected response (antagonistic action).

However, other characteristics are more specific for each of the solvents used: 1 ) For CC:PPA the linear effect of the variables $T$ and $S$ show strong values, meanwhile the effect of $t$ is negligible in almost all response criteria, but for CC:BA the linear effect of $t$ increases, reaching nearly the relevance of the variable $T .2$ ) The quadratic or non-linear effect shows a strong effect in the $S$ variable for CC:BA, meanwhile in the CC:PPA the strongest effect is registered in the $T$ variable; and 3 ) Regarding the interactive effects, for the CC:PPA the interactions of the variable $t$ with the other variables ( $t T$ and $t S$ ) showed a minor relevance, meanwhile for the CC:BA the $t T$ interaction showed a strong significance in the description of the behavior of almost all responses.

\subsubsection{Overall effects of the extraction variables on the target responses}

Although parametric results can depict the patterns of the responses, 3D and 2D graphical representations support their understanding. Fig. 2 shows the graphical results in terms of the response surfaces of the total compounds content in $\mathrm{mg} / \mathrm{g}$ dw determined by HPLC (P1 + P2 + P3) for both DES. Each column is divided into two subsections (A and B). Part A shows the joint graphical 3D analysis as a function of each of the variables involved. Each net surface represents the theoretical three-dimensional response surface predicted with the second order polynomial of Eqs. (5) and (9), respectively. The statistical design and results are described in Table 2. Estimated parametric values are shown in Table 3. The binary actions between variables are presented when the excluded variable is positioned at the optimum of the experimental domain (Table 4). Part B illustrates the goodness of fit, using two basic graphical statistic criteria. The first one, the ability to simulate the changes of the response between the predicted and observed data; and the second one, the residual distribution as a function of each of the variables. Note all the differences in the axes scales.

In similar terms, Fig. 3 illustrates the results $(\mathrm{mg} / \mathrm{g} \mathrm{dw})$ for the identified HPLC peaks of P1 (3-O-caffeoylquinic acid content), P2 (quercetin 3-O-glucoside content) and P3 (quercetin $O$-pentoside content). Fig. 3 illustrates a 3D response surface plots predicted with their respective second order polynomial equation described by Eq. (1). Each of the net surfaces, representing the theoretical three-dimensional response surface, were built with Eqs. (2)-(4) for the CC:BA system and Eqs. (6)-(8) for CC:PPA. The subsection related with the statistical results of the individual responses is eluded in those figures, but estimated parametric values, confidence of intervals and statistical coefficients of the fitting procedure performed are shown in Table 3.

Observing all the plots in Fig. 2 it is possible to verify that the amount of extracted material increases to an optimum value and, in most cases, decreases as a function of each assessed independent variable. Similar behavior can be found in Fig. 3, and in consequence in almost all combinations the optimum value can be found in single points, which allows computing the conditions that lead to an absolute maximum.

3.2.3. Numerical individual and global optimal conditions that maximize the extraction, statistical analysis and experimental verification of predictive models

The performed optimization of the HAE response by RSM provides a strong solution that minimizes the errors with a short number of experimental trials as has been demonstrated elsewhere (Roselló-Soto et al., 2015; Wong et al., 2015). The multivariable fitting decreases the number of parameters needed to analyze the response leading to better estimations, reducing their interval of confidence and allowing predicting the response behavior. In addition, by applying a simple procedure (considering restrictions to the experimental ranges) the individual optimal conditions are found, as well as the maximal response values (Table 4) in relative (marked with * when the optimal value may be outside of the experimental range studied) or absolute optimal conditions were found for all the responses.

Finally, Fig. 4 simplifies the interpretation of the influence of the independent variables in a bi-dimensional representation of the optimal conditions of the RSM variables. The line represents the variable response pattern when the others are located at the optimal values, the operating conditions that maximize the extraction conditions are represented with dots $(\odot)$; these singular conditions are represented in Table 4 to clarify not only the optimal independent variables conditions but also the optimal values predicted. The conditions that lead to the optimal values were re-checked to ensure the accuracy of the presented results. Generally, CC:BA gave significantly higher values than CC:PPA probably due to the lack of solubility of these compounds in the water that can be incorporated into CC:PPA.

\subsection{Dose-response analysis of the solid-to-liquid effect at the optimum conditions}

The effect of the variable $S / L$ was studied in a dose-response format for all the HAE responses at the optimal global conditions predicted for the BA and PPA solvents by the polynomial Eqs. (2)-(0) (Table 4). Preliminary results performed, showed that the experimental limit value at lab-scale was close to $140 \mathrm{~g} / \mathrm{L}$. Therefore, in both techniques an 
BUTYRIC ACID

\section{A: JOINT ANALYSIS}
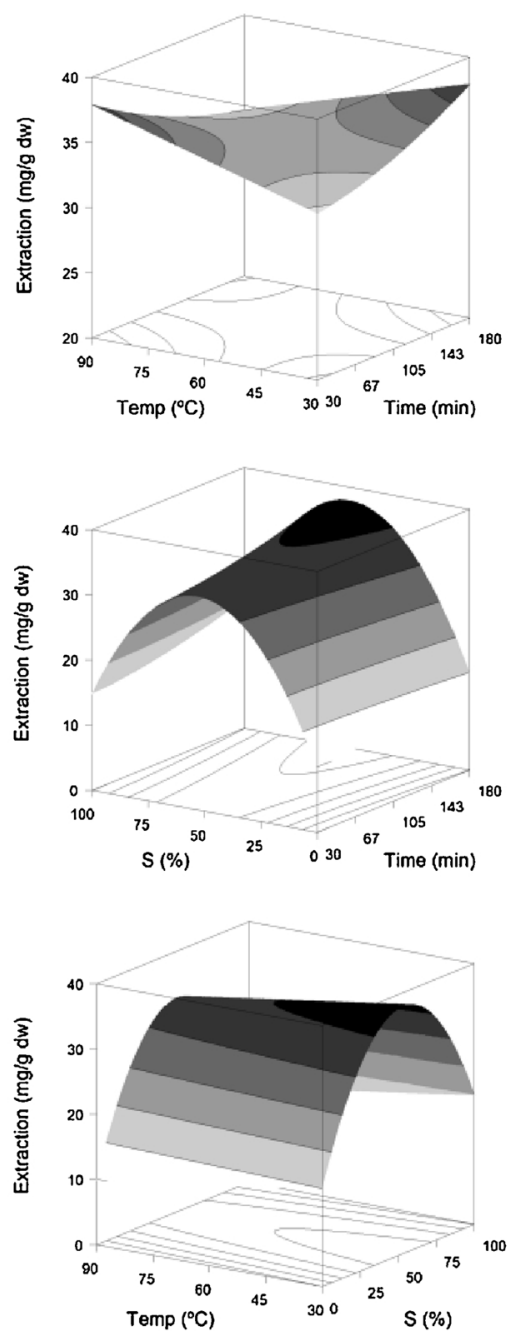

\section{B: STATISTICAL DISTRIBUTION}

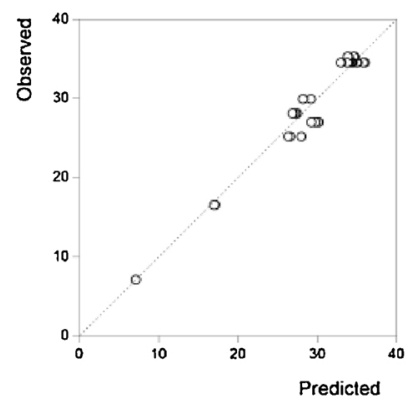

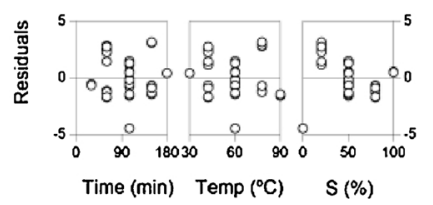

\section{PHENYLPROPIONIC ACID}

\section{A: JOINT ANALYSIS}
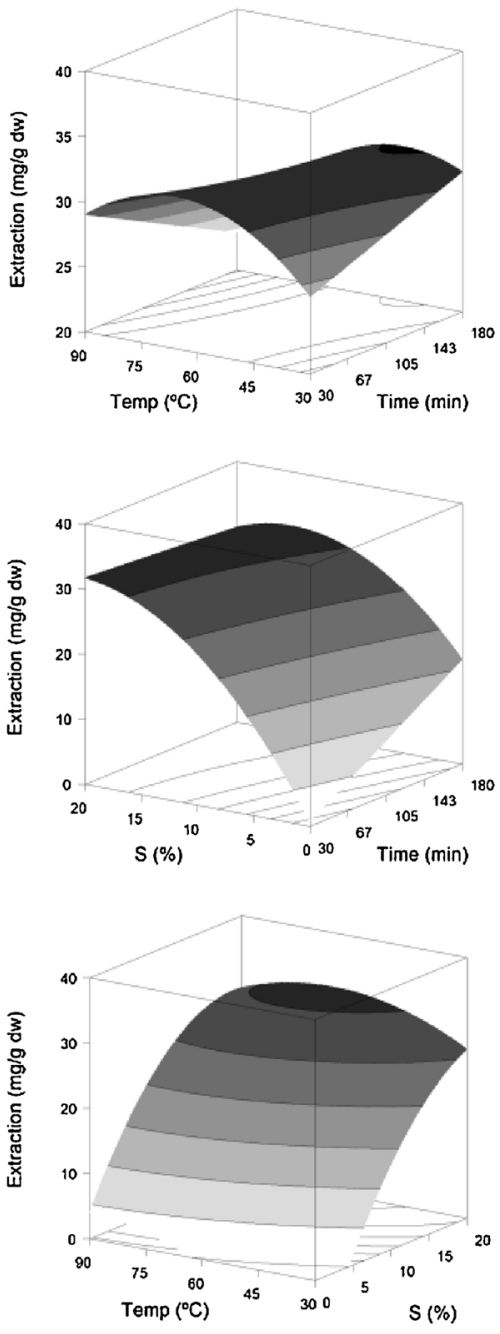

\section{B: STATISTICAL DISTRIBUTION}
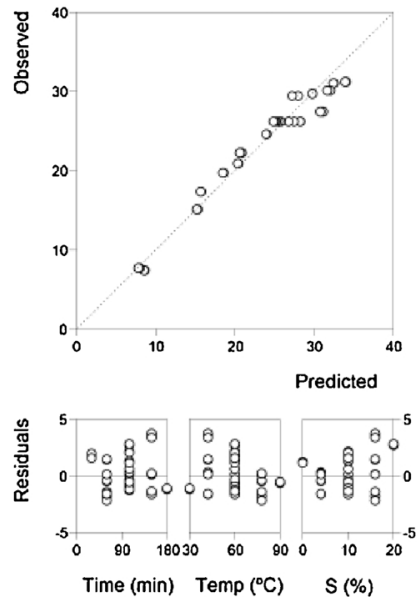

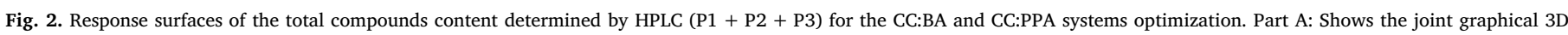

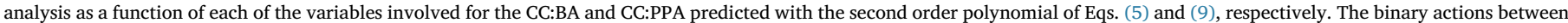

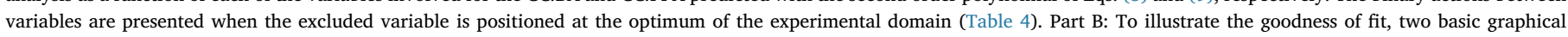

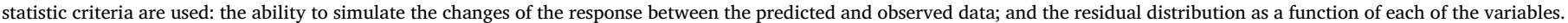


Table 4

Operating optimal conditions of the variables involved that maximize the response values for RSM using a CCCD for each of the extracting techniques assessed (CC:BA and CC:PPA), for the three individual response value formats of each compound and for all the compounds. Response criteria comprise the following: 1) HPLC quantification of 3-O-caffeoylquinic acid content (P1), quercetin 3-O-glucoside content (P2), quercetin $O$-pentoside content (P3) and total HPLC content (TOTAL, P1 + P2 + P3).

\begin{tabular}{|c|c|c|c|c|}
\hline \multirow[t]{2}{*}{ CRITERIA } & \multicolumn{3}{|c|}{ OPTIMAL VARIABLE CONDITIONS } & \multirow[t]{2}{*}{ OPTIMUM $(m g / g d w)$} \\
\hline & $X_{1}: t(\min )$ & $X_{2}: T\left({ }^{\circ} \mathrm{C}\right)$ & $X_{3}: S(\%)$ & \\
\hline \multicolumn{5}{|c|}{ Individual optimal variable conditions for 3-O-caffeoylquinic acid (P1): } \\
\hline$C C: B A$ & *180.0 & $* 30.0$ & 68.6 & $7.0 \pm 1.4 \mathrm{mg} / \mathrm{g} \mathrm{dw}$ \\
\hline$C C: P P A$ & *180.0 & 59.5 & $* 20.0$ & $6.0 \pm 3.9 \mathrm{mg} / \mathrm{g} \mathrm{dw}$ \\
\hline \multicolumn{5}{|c|}{ Individual optimal variable conditions for the quercetin 3-O-glucoside (P2): } \\
\hline$C C: B A$ & *180.0 & $* 30.0$ & 49.3 & $16.0 \pm 4.2 \mathrm{mg} / \mathrm{g} \mathrm{dw}$ \\
\hline$C C: P P A$ & *180.0 & 67.5 & 16.6 & $15.6 \pm 5.1 \mathrm{mg} / \mathrm{g} \mathrm{dw}$ \\
\hline \multicolumn{5}{|c|}{ Individual optimal variable conditions for the quercetin O-pentoside (P3): } \\
\hline$C C: B A$ & *180.0 & 52.7 & 44.9 & $13.1 \pm 3.1 \mathrm{mg} / \mathrm{g} \mathrm{dw}$ \\
\hline$C C: P P A$ & *30.0 & 53.8 & $* 20.0$ & $14.8 \pm 4.9 \mathrm{mg} / \mathrm{g} \mathrm{dw}$ \\
\hline \multicolumn{5}{|c|}{ Global optimal variable conditions for the total HPLC compounds $(P 1+P 2+P 3)$} \\
\hline$C C: B A$ & *180.0 & $* 30.0$ & 53.0 & $37.9 \pm 4.0 \mathrm{mg} / \mathrm{g} \mathrm{dw}$ \\
\hline$C C: P P A$ & *30.0 & 55.7 & $* 20.0$ & $31.7 \pm 4.2 \mathrm{mg} / \mathrm{g} \mathrm{dw}$ \\
\hline
\end{tabular}

experimental dose-response test was designed to evaluate the $S / L$ behavior between $5 \mathrm{~g} / \mathrm{L}$ to $140 \mathrm{~g} / \mathrm{L}$ using ten different concentrations (data not shown). In all cases, the $S / L$ effect can be described by a simple linear relationship with an intercept and in all cases the linear relation shows decreasing patterns as a function of the increase of $S / L$. However, in all cases, the decreasing patterns explained by the parametric coefficient of the slope were non-significant at confidence interval level of $95 \%(\alpha=0.05)$ and the decreasing effect was rejected for further analysis. Although the conclusions of the analysis are excluded, in global terms it can be postulated that the increase of the $S / L$ has a slight effect on the phenolic compound extraction and no saturation effects seem to appear at least up to $140 \mathrm{~g} / \mathrm{L}$.

\subsection{Comparison with other responses reported using non-DES}

To the best of our knowledge there are no previous works that have used DES as alternative solvents for the extraction of these compounds. The solid-liquid extraction of the compounds here studied is usually carried out using organic solvents such as methanol, ethanol, acetone and ethyl acetate (Kerton, 2009). In particular, the most common solvents used by researchers are aqueous methanol and ethanol (Bravo and Mateos, 2008). In the scientific literature, there are several techniques that also describe the extraction of these compounds with non-DES solvents, in which the relevant ones are summarized hereafter:

- Compound P1 is found in small amounts in several natural matrices. Using the same plant source ( $J$. regia leaves) authors have found similar amounts as those here described $(7.0$ and $6.0 \mathrm{mg} / \mathrm{g} \mathrm{dw}$ for CC:BA and CC:PPA, respectively). As example, Santos et al. (2013) using hydro-alcoholic mixtures found $6.41 \mathrm{mg} / \mathrm{g} \mathrm{dw}$, meanwhile Vieira et al. (2017) achieved a maximum of $10.7 \mathrm{mg} / \mathrm{g} \mathrm{dw}$. In other natural sources such as in Vaccinium floribundum Kunth berries were found $0.015 \mathrm{mg} / \mathrm{g} \mathrm{dw}$ (Prencipe et al., 2014), 0.76 and $0.89 \mathrm{mg} / \mathrm{g}$ dw in Lonicera japonica Thunb. flowers (Li et al., 2014) and $17.2 \mathrm{mg}$ / $\mathrm{g} \mathrm{dw}$ on Solanum betaceum skin extract (Orqueda et al., 2017).

- For compound P2 the quantities recovered using J. regia leaves by other authors (Vieira et al., 2017) (13.2 and $15.2 \mathrm{mg} / \mathrm{g} \mathrm{dw}$, using hydro-alcoholic mixtures) are slightly lower than those found here using DES (16.0 and $15.6 \mathrm{mg} / \mathrm{g}$ dw for CC:BA and CC:PPA, respectively). In other material sources, higher values are reported such as $33.40 \mathrm{mg} / \mathrm{g} \mathrm{dw}$ in Securigera securidaca flowers (Ibrahim et al., 2015) and $36.7 \mathrm{mg} / \mathrm{g}$ dw in Dasiphora fruticosa (L.) Rydb. (Tomczyk et al., 2012).
- For compound P3 the quantities recovered using J. regia leaves by other authors (Vieira et al., 2017) (12.7 and $15.1 \mathrm{mg} / \mathrm{g} \mathrm{dw}$, using water/ethanol mixtures) are similar to those found here using DES (13.1 and $14.8 \mathrm{mg} / \mathrm{g} \mathrm{dw}$ for CC:BA and CC:PPA, respectively). Lower amounts were recovered from other material sources such as $0.0133 \mathrm{mg} / \mathrm{g} \mathrm{dw}$ on Rosa canina hips (Cunja et al., 2015) and $0.101 \mathrm{mg} / \mathrm{g}$ fw in $V$. floribundum berries (Prencipe et al., 2014).

Compared to more traditional water/ethanol reference solvent, similar or higher extraction yields were obtained using the selected DES.

This work provides valuable insights on the use of DES formed between choline chloride and carboxylic acids, not only as extracting solvents, but also as potential formulation media, avoiding an intermediate recovery step of the bioactive compounds from the solvent. In this regard, the design of the final composition of the solvent should take into consideration the compatibility issues with the desired final application.

\section{Conclusions}

The combined effects of three independent variables were studied to maximize the intrinsic responses on the $J$. regia chemical composition. A $C C C D$ of three factors with five-levels of 16 combinations and 6 replicates at the center of the experimental domain was successfully applied for the solvent optimization by RSM. Polynomial responses were designed and experimentally verified on 3-O-caffeoylquinic acid (P1), quercetin 3-O-glucoside (P2), quercetin $O$-pentoside (P3) and total HPLC (sum of the most abundant compounds: P1, P2 and P3) extraction. Comparatively, for all the assessed responses, CC:BA results in higher extraction yields than CC:PPA.

The water content was clearly the most relevant extraction variable, followed by temperature and, lastly, extraction time. Considering the study of the solid/liquid ratio effect, an important variable from an industrial point of view, no significant decreasing patterns were observed for any of the studied responses in the 5-120 g/L range. Because of the increased demand for industrial production of bioactive compounds, the effect of each variable on the optimum value is a practical information. Usually, laboratory scale up units are slightly less efficient than those obtained at industrial level. However, the profiles of the physical-chemical variables involved remain and therefore, can be used as a valuable illustration to transfer the results found at a lab-scale to an industrial environment. Other variables can be included to the models developed to reduce the industrial costs (ie. energy, materials and time consumption) highly influencing the profitable viability of the process.

Therefore, this work studied the effect of the acid's molecular structure (as hydrogen bond donor in a CC based DES) on the extraction of phytochemical compounds from $J$. regia L., followed by the optimization of the extraction conditions by RSM using HAE for the best DES.

\section{Acknowledgements}

The authors thank the Foundation for Science and Technology (FCT, Portugal) and FEDER under Programme PT2020 for financial support to CIMO (UID/AGR/00690/2013), V. Vieira (SFRH/BD/108487/2015) grant and L. Barros contract. To project POCI-01-0145-FEDER-006984 Associate Laboratory LSRE-LCM funded by FEDER through COMPETE2020 - Programa Operacional Competitividade e Internacionalização (POCI) - and by national funds through FCT Fundação para a Ciência e a Tecnologia. To project CICECO-Aveiro Institute of Materials POCI-01-0145-FEDER-007679 (FCT Ref. UID/ CTM/50011/2013), financed by national funds through the FCT/MEC and when appropriate co-financed by FEDER under the PT2020 Partnership Agreement. This work is funded by the European Structural and Investment Funds (FEEI) through POCI, within the scope of Project POCI $n^{\circ}$ 030463. To Xunta de Galicia for financial support for the postdoctoral researcher of M.A. Prieto. 


\section{BUTYRIC ACID}
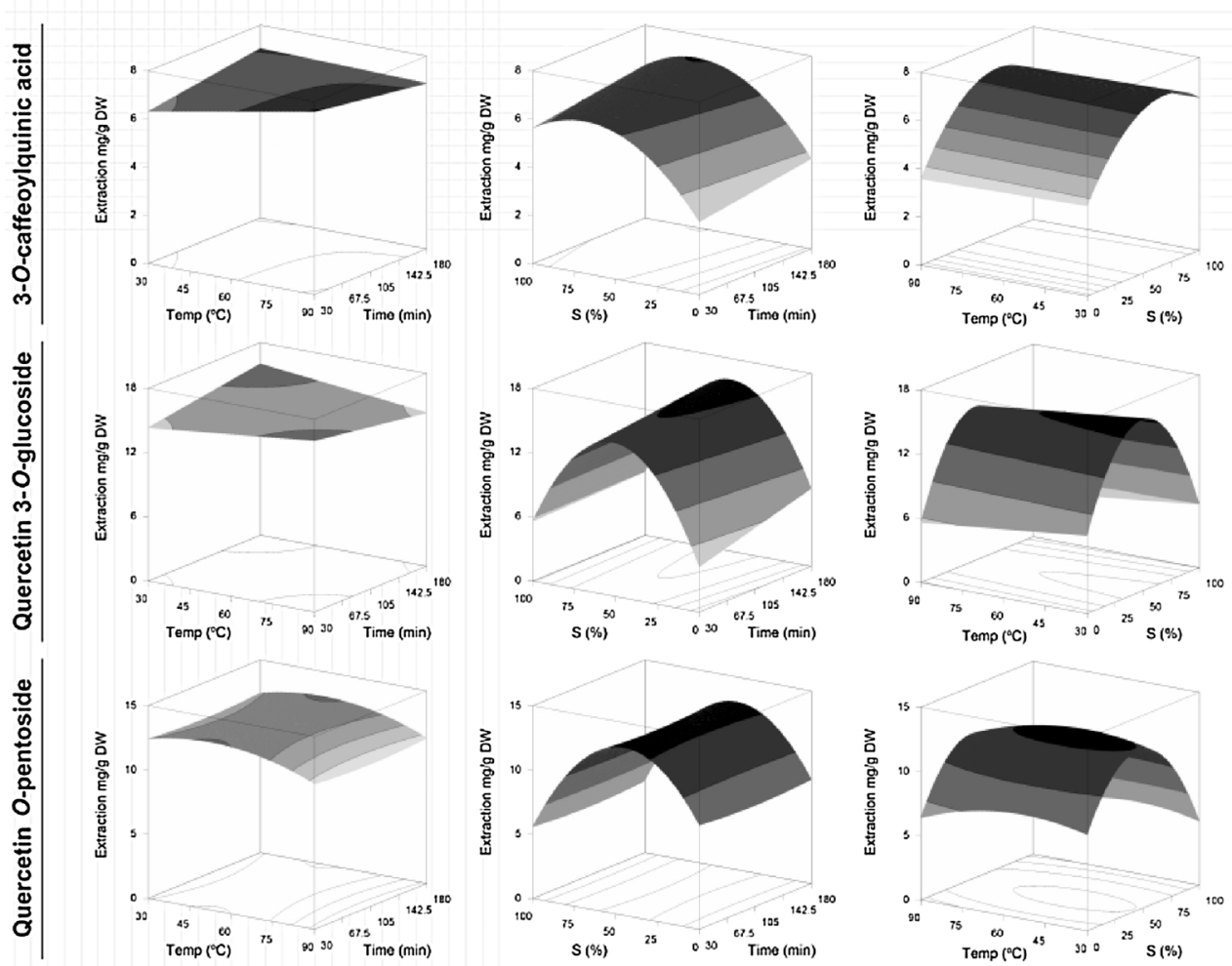

PHENYLPROPIONIC ACID
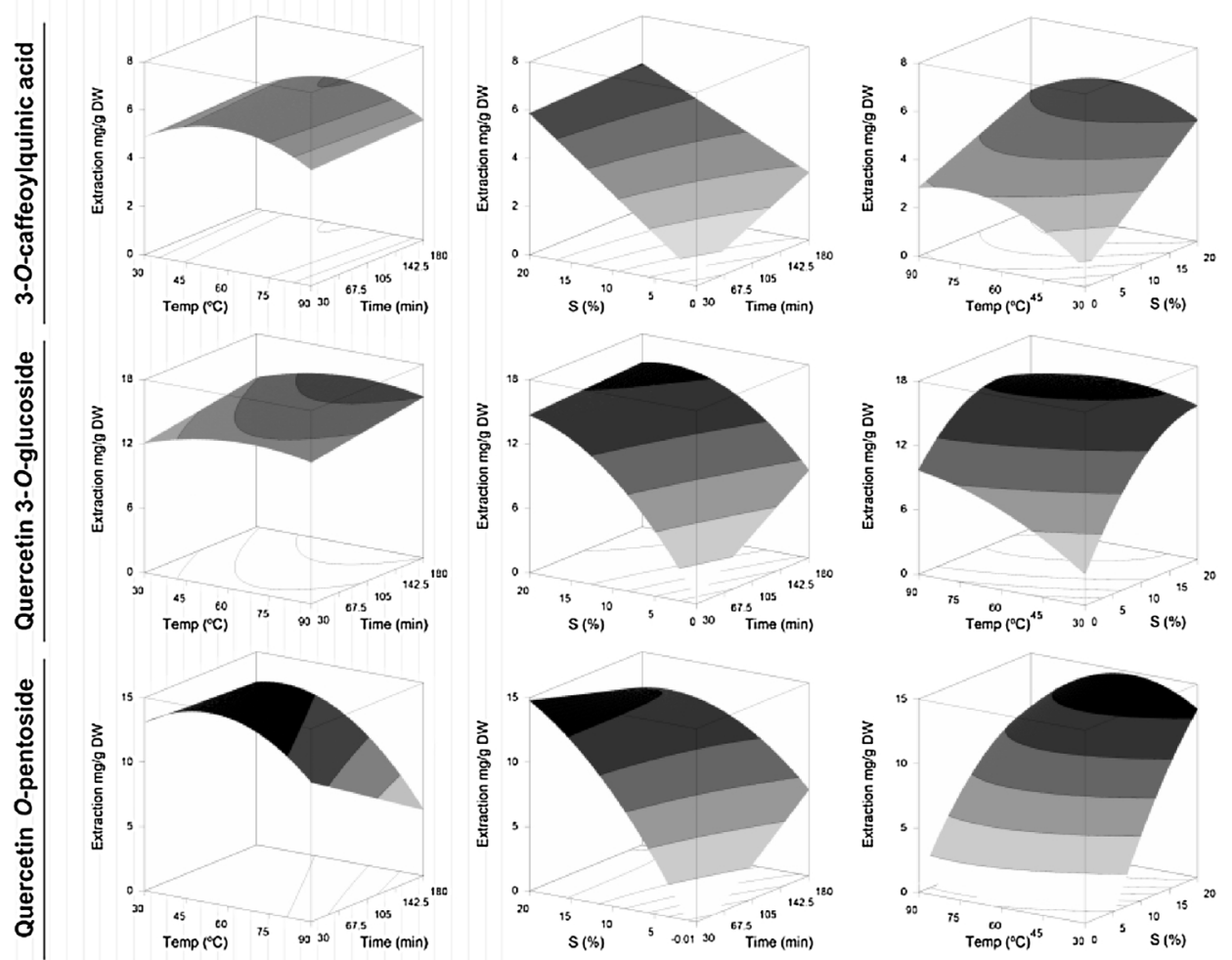

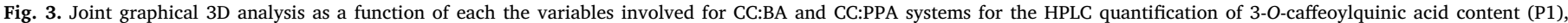
quercetin 3-O-glucoside content (P2) and quercetin $\mathrm{O}$-pentoside content (P3). 


\section{BUTYRIC ACID}
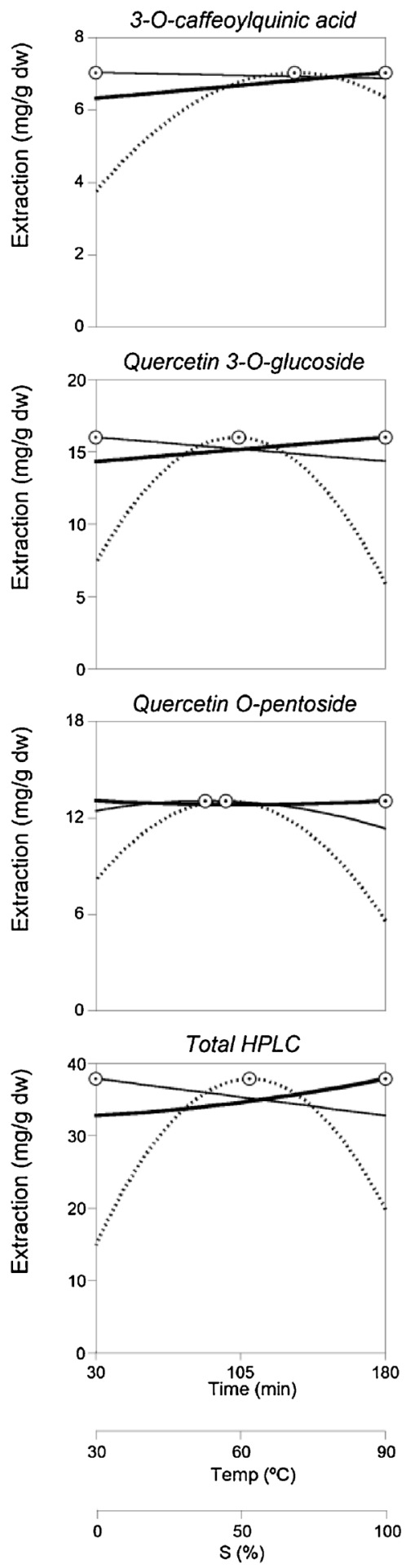

\section{PHENYLPROPIONIC ACID}
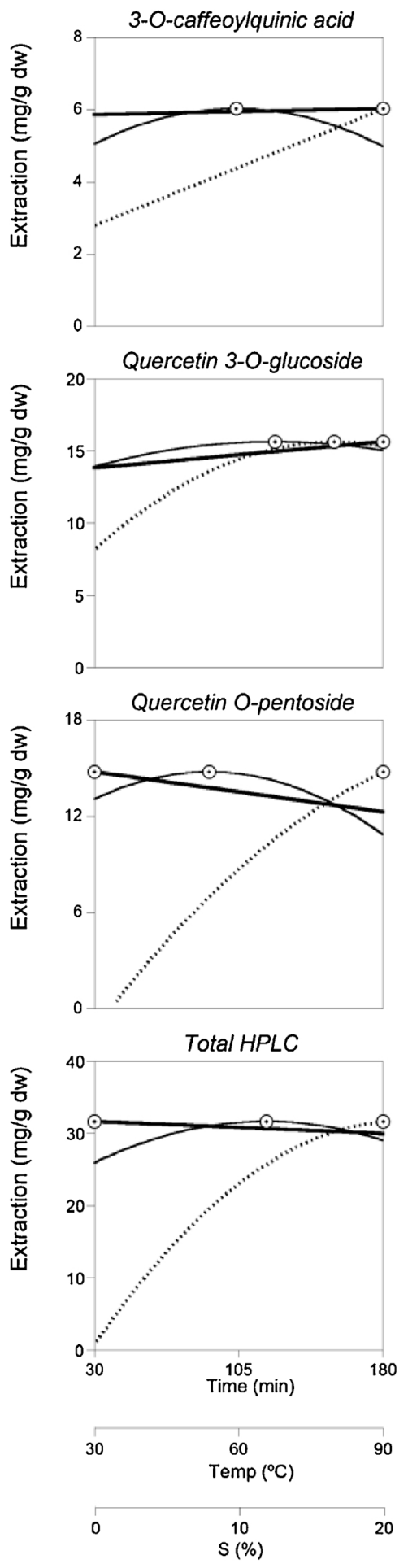

Temp $\left({ }^{\circ} \mathrm{C}\right)$

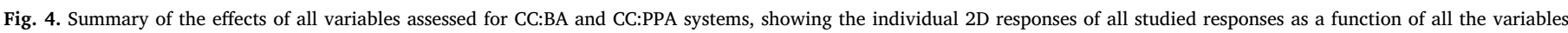

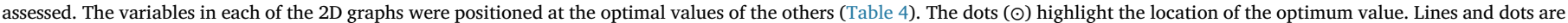
generated by the theoretical second order polynomial models of Eqs. (2)-(5) for CC:BA and (6)-(9) for CC:PPA. 


\section{Appendix A. Supplementary data}

Supplementary data associated with this article can be found, in the online version, at https://doi.org/10.1016/j.indcrop.2018.02.029.

\section{References}

Abbott, A.P., Capper, G., Davies, D.L., Rasheed, R.K., Tambyrajah, V., 2003. Novel solvent properties of choline chloride/urea mixtures. Chem. Commun. 99, 70-71. http://dx. doi.org/10.1039/b210714g.

Abbott, A.P., Boothby, D., Capper, G., Davies, D.L., Rasheed, R.K., 2004. Deep eutectic solvents formed between choline chloride and carboxylic acids: versatile alternatives to ionic liquids. J. Am. Chem. Soc. 9142-9147.

Barros, L., Pereira, E., Calhelha, R.C., Dueñas, M., Carvalho, A.M., Santos-Buelga, C., Ferreira, I.C.F.R., 2013. Bioactivity and chemical characterization in hydrophilic and lipophilic compounds of Chenopodium ambrosioides L. J. Funct. Foods 5, 1732-1740. http://dx.doi.org/10.1016/j.jff.2013.07.019.

Bezerra, M.A., Santelli, R.E., Oliveira, E.P., Villar, L.S., Escaleira, E.A., Escaleira, L.A., 2008. Response surface methodology (RSM) as a tool for optimization in analytical chemistry. Talanta 76, 965-977.

Box, G., Hunter, J., 1957. Multi-factor experimental designs for exploring response surfaces. Ann. Math. Stat. 28, 195-241.

Bravo, L., Mateos, R., 2008. Analysis of flavonoids in functional foods and nutraceuticals. In: Hurst, W.J. (Ed.), Methods of Analysis for Functional Foods and Nutraceuticals. CRC Press, pp. 148-206.

Carvalho, M., Ferreira, P.J., Mendes, V.S., Silva, R., Pereira, J.A., Jerónimo, C., Silva, B.M., 2010. Human cancer cell antiproliferative and antioxidant activities of Juglans regia L. Food Chem. Toxicol. 48, 441-447. http://dx.doi.org/10.1016/j.fct.2009.10. 043.

Choi, Y.H., van Spronsen, J., Dai, Y., Verberne, M., Hollmann, F., Arends, I.W.C.E., Witkamp, G.-J., Verpoorte, R., 2011. Are natural deep eutectic solvents the missing link in understanding cellular metabolism and physiology? Plant Physiol. 156, 1701-1705. http://dx.doi.org/10.1104/pp.111.178426.

Cunja, V., Mikulic-Petkovsek, M., Zupan, A., Stampar, F., Schmitzer, V., 2015. Frost decreases content of sugars, ascorbic acid and some quercetin glycosides but stimulates selected carotenes in Rosa canina hips. J. Plant Physiol. 178, 55-63.

Dai, J., Mumper, R.J., 2010. Plant phenolics: extraction, analysis and their antioxidant and anticancer properties. Molecules 15, 7313-7352. http://dx.doi.org/10.3390/ molecules15107313.

Dai, Y., Rozema, E., Verpoorte, R., Choi, Y.H., 2016. Application of natural deep eutectic solvents to the extraction of anthocyanins from Catharanthus roseus with high extractability and stability replacing conventional organic solvents. J. Chromatogr. A 1434, 50-56. http://dx.doi.org/10.1016/j.chroma.2016.01.037.

Erdemoglu, N., Küpeli, E., Yeşilada, E., 2003. Anti-inflammatory and antinociceptive activity assessment of plants used as remedy in Turkish folk medicine. J. Ethnopharmacol. 89, 123-129. http://dx.doi.org/10.1016/S0378-8741(03)00282-4.

Ferreira, S.L.C., Bruns, R.E., Ferreira, H.S., Matos, G.D., David, J.M., Brandão, G.C., da Silva, E.G.P., Portugal, L.A., dos Reis, P.S., Souza, A.S., dos Santos, W.N.L., 2007. BoxBehnken design: an alternative for the optimization of analytical methods. Anal. Chim. Acta 597, 179-186.

Francisco, M., Van Den Bruinhorst, A., Kroon, M.C., 2012. Green chemistry new natural and renewable low transition temperature mixtures (LTTMs): screening as solvents for lignocellulosic biomass processing. Green Chem. 14, 2153-2157. http://dx.doi. org/10.1039/c2gc35660k.

Francisco, M., van den Bruinhorst, A., Kroon, M.C., 2013. Low-Transition-Temperature Mixtures (LTTMs): a new generation of designer solvents. Angew. Chem. - Int. Ed. 52, 3074-3085. http://dx.doi.org/10.1002/anie.201207548.

García, Aránzazu, Rodríguez-Juan, Elisa, Rodríguez-Gutiérrez, Guillermo, Rios, J.J., Fernández-Bolaños, J.J., 2016. Extraction of phenolic compounds from virgin olive oil by deep eutectic solvents (DESs). Food Chem. 197, 554-561. http://dx.doi.org/ 10.1016/j.foodchem.2015.10.131.

Gu, T., Zhang, M., Tan, T., Chen, J., Li, Z., Zhang, Q., Qiu, H., 2014. Deep eutectic solvents as novel extraction media for phenolic compounds from model oil. Chem. Commun. 50, 11749-11752. http://dx.doi.org/10.1039/c4cc04661g.

Heleno, S.A., Diz, P., Prieto, M.A., Barros, L., Rodrigues, A., Barreiro, M.F., Ferreira, I.C.F.R., 2016. Optimization of ultrasound-assisted extraction to obtain mycosterols from Agaricus bisporus L. by response surface methodology and comparison with conventional Soxhlet extraction. Food Chem. 197, 1054-1063.

Ibrahim, R.M., El-Halawany, A.M., Saleh, D.O., Naggar, E.M.B., El El-Shabrawy, A.E.R.O., El-Hawary, S.S., 2015. HPLC-DAD-MS/MS profiling of phenolics from Securigera securidaca flowers and its anti-hyperglycemic and anti-hyperlipidemic activities. Rev. Bras. Farmacogn. 25, 134-141.

Jancheva, M., Grigorakis, S., Loupassaki, S., Makris, D.P., 2017. Optimised extraction of antioxidant polyphenols from Satureja thymbra using newly designed glycerol-based natural low-transition temperature mixtures (LTTMs). J. Appl. Res. Med. Aromat. Plants 1-10.
Kalil, S., Maugeri, F., 2000. Response surface analysis and simulation as a tool for bioprocess design and optimization. Process Biochem. 35, 539-550.

Kemmer, G., Keller, S., 2010. Nonlinear least-squares data fitting in excel spreadsheets. Nat. Protoc. 5, 267-281.

Kerton, F.M., 2009. Alternative Solvents for Green Chemistry. Royal Society of Chemistry Cambridge.

Li, J., Jin, S., Zu, Y.-G., Luo, M., Wang, W., Zhao, C.-J., Fu, Y.-J., 2014. Rapid preparative extraction and determination of major organic acids in honeysuckle (Lonicera japonica Thunb.) tea. J. Food Compos. Anal. 33, 139-145.

Mbous, Y.P., Hayyan, M., Hayyan, A., Wong, W.F., Hashim, M.A., Looi, C.Y., 2017. Applications of deep eutectic solvents in biotechnology and bioengineering-promises and challenges. Biotechnol. Adv. 35, 105-134. http://dx.doi.org/10.1016/j. biotechadv.2016.11.006.

Nam, M., Zhao, J., Lee, M., Jeong, J., Lee, J., 2015. Enhanced extraction of bioactive natural products using tailor-made deep eutectic solvents: application to flavonoid extraction from Flos sophorae. Green Chem. 17, 1718-1727. http://dx.doi.org/10. 1039/c4gc01556h.

Orqueda, M.E., Rivas, M., Zampini, I.C., Alberto, M.R., Torres, S., Cuello, S., Sayago, J., Thomas-Valdes, S., Jiménez-Aspee, F., Schmeda-Hirschmann, G., Isla, M.I., 2017. Chemical and functional characterization of seed pulp and skin powder from chilto (Solanum betaceum), an Argentine native fruit. Phenolic fractions affect key enzymes involved in metabolic syndrome and oxidative stress. Food Chem. 216, 70-79.

Paradiso, V.M., Clemente, A., Summo, C., Pasqualone, A., Caponio, F., 2016. Towards green analysis of virgin olive oil phenolic compounds: extraction by a natural deep eutectic solvent and direct spectrophotometric detection. Food Chem. 212, 43-47. http://dx.doi.org/10.1016/j.foodchem.2016.05.082.

Pena-Pereira, F., Namieśnik, J., 2014. Ionic liquids and deep eutectic mixtures: sustainable solvents for extraction processes. ChemSusChem Rev 7, 1784-1800. http://dx. doi.org/10.1002/cssc.201301192.

Pinela, J., Prieto, M.A., Barreiro, M.F., Carvalho, A.M., Oliveira, M.B.P.P., Vázquez, J.A., Ferreira, I.C.F.R., 2016. Optimization of microwave-assisted extraction of hydrophilic and lipophilic antioxidants from a surplus tomato crop by response surface methodology. Food Bioprod. Process. 98, 283-298.

Pinela, J., Prieto, M.A., Antonio, A.L., Carvalho, A.M., Oliveira, M.B.P.P., Barros, L, Ferreira, I.C.F.R., 2017. Ellagitannin-rich bioactive extracts of Tuberaria lignosa: insights into the radiation-induced effects in the recovery of high added-value compounds. Food Funct. 8, 2485.

Prencipe, F.P., Bruni, R., Guerrini, A., Rossi, D., Benvenuti, S., Pellati, F., 2014 Metabolite profiling of polyphenols in Vaccinium berries and determination of their chemopreventive properties. J. Pharm. Biomed. Anal. 89, 257-267.

Prieto, M.A., Vázquez, J.A., Murado, M.A., 2014. A critical point: the problems associated with the variety of criteria to quantify the antioxidant capacity. J. Agric. Food Chem. 62, 5472-5484. http://dx.doi.org/10.1021/jf5005995.

Prieto, M.A., Vázquez, J.A., Murado, M.A., 2015. A new and general model to describe, characterize, quantify and classify the interactive effects of temperature and $\mathrm{pH}$ on the activity of enzymes. Analyst 140, 3587-3602.

Ranic, M., Nikolic, M., Pavlovic, M., Buntic, A., Siler-Marinkovic, S., DimitrijevicBrankovic, S., 2014. Optimization of microwave-assisted extraction of natural antioxidants from spent espresso coffee grounds by response surface methodology. J. Clean. Prod. 80, 69-79.

Roselló-Soto, E., Galanakis, C.M., Brnčić, M., Orlien, V., Trujillo, F.J., Mawson, R., Knoerzer, K., Tiwari, B.K., Barba, F.J., 2015. Clean recovery of antioxidant compounds from plant foods, by-products and algae assisted by ultrasounds processing. Modeling approaches to optimize processing conditions. Trends Food Sci. Technol. 42, 134-149.

Ruesgas-Ramón, M., Figueroa-Espinoza, M.C., Durand, E., 2017. Application of Deep Eutectic Solvents (DES) for phenolic compounds extraction: overview, challenges, and opportunities. J. Agric. Food Chem. 65, 3591-3601. http://dx.doi.org/10.1021/ acs.jafc.7b01054.

Santos, A., Barros, L., Calhelha, R.C., Duenas, M., Carvalho, A.M., Santos-buelga, C., Ferreira, I.C.F.R., 2013. Leaves and decoction of Juglans regia L.: different performances regarding bioactive compounds and in vitro antioxidant and antitumor effects. Ind. Crop. Prod. 51, 430-436.

Smith, E.L., Abbott, A.P., Ryder, K.S., 2014. Deep Eutectic Solvents (DESs) and their applications. Chem. Rev. 114, 11060-11082.

Tomczyk, M., Bazylko, A., Bonarewicz, J., 2012. Method development and validation for optimized separation of quercetin derivatives in selected Potentilla species using high-performance thin-layer chromatography photodensitometry method. J. Pharm. Biomed. Anal. 61, 265-270.

Vieira, V., Prieto, M.A., Barros, L., Coutinho, J.A.P., Ferreira, O., Ferreira, I.C.F.R., 2017. Optimization and comparison of maceration and microwave extraction systems for the production of phenolic compounds from Juglans regia L for the valorization of walnut leaves. Ind. Crops Prod. 107, 341-352.

Wong, W.H., Lee, W.X., Ramanan, R.N., Tee, L.H., Kong, K.W., Galanakis, C.M., Sun, J., Prasad, K.N., 2015. Two level half factorial design for the extraction of phenolics, flavonoids and antioxidants recovery from palm kernel by-product. Ind. Crops Prod. $63,238-248$. 